DOI: 10.12957/demetra.2015.13856

\title{
Estudo comparativo da couve minimamente processada e in natura, segundo aspectos de qualidade microbiológica
}

\section{Comparative study of minimally processed and in natura cole, according to microbiological quality issues}

Kécia Rejany da Silva Batista Santos' Cleide Novais da Silva Teixeira? Nivaldo Morais Viana Júnior? Renata Ferreira Santana' Adriana da Silva Miranda' Rita Graziella Coutinho?

I Faculdade de Tecnologia e Ciências de Vitória da Conquista. Curso de Nutrição. Vitoria da Conquista, BA - Brasil.

Correspondência / Correspondence Nivaldo Morais Viana Júnior

E-mail: nivaldojuniorrr@hotmail.com

\section{Resumo}

As hortaliças fazem parte da alimentação complementar do ser humano. A couve é muito apreciada na mesa do brasileiro, por ser de fácil cultivo e encontrada durante todo ano em feiras livres e gôndolas de supermercados. Comercializada de forma in natura e minimamente processada, a couve é um veículo importante de contaminação por microrganismos patogênicos, ocasionando doença transmitida por alimento (DTA) se não higienizada corretamente. Sendo assim, este estudo tem como objetivo analisar a qualidade microbiológica da couve minimamente processada e a couve in natura, comparando os níveis de contaminações entre elas. Para isto, foram coletadas amostras de couves em barracas situadas em dois corredores de uma feira livre em Vitória da Conquista-BA. Realizou-se análise para aeróbios mesófilos, Staphylococcus aureus, coliformes totais, bolores e leveduras, todos utilizando a técnica de petrifilm. Das amostras analisadas, todas se encontravam contaminadas em relação aos microrganismos pesquisados, tornando a couve tanto in natura quanto a minimamente processada não apta para o consumo humano, se não forem aplicadas técnicas adequadas de higienização e sanitização.

Palavras-chave: Brassica. Análise Microbiológica. Microbiologia de Alimentos. Contaminação de Alimentos. 


\section{Abstract}

Vegetables are part of the complementary feeding of human beings. Cole is very appreciated by Brazilians, being easy to grow and found throughout the year in street markets and supermarket shelves. Marketed so fresh and minimally processed, cole is an important vehicle of contamination by pathogenic microorganisms, causing disease transmitted by food (DTA) if not properly sanitized. Thus, this study aims to analyze the microbiological quality of minimally processed cole and fresh cole, comparing the levels of contamination between them. For this, cole samples were collected in tents located in two halls of a free fair in Vitória da Conquista-BA, Brazil. We conducted analysis for aerobic mesophilic, Staphylococcus aureus, total coliforms, molds and yeasts, all using the petrifilm technique. Of the samples analyzed, all were contaminated with respect to microorganisms examined, making cole both in natura as minimally processed unfit for human consumption if proper techniques of cleaning and sanitizing are not applied.

Key words: Brassica. Microbiological Analysis. Food Microbiology. Food Contamination.

\section{Introdução}

A couve (Brassica oleracea) é uma hortaliça originária do mediterrâneo que pertence à família das Brassicas. Apresenta enorme demanda em médios e grandes centros urbanos, fácil de ser cultivada e sendo encontrada o ano inteiro. Rica em vitaminas, minerais e fibras, apresenta alto teor de ferro e vitamina $\mathrm{C}$, favorecendo a absorção desse mineral no organismo. ${ }^{1-3}$

Há grande interesse na produção de frutas e hortaliças minimamente processadas, em razão das transformações no estilo de vida da população, que diminuiu o tempo disponível para preparação de alimentos, sobretudo vegetais, tanto no âmbito familiar, como nas unidades de alimentação e nutrição. Para o consumidor, os alimentos devem ser saudáveis, práticos e seguros. No Brasil, vários são os produtos utilizados minimamente processados, e sendo a couve altamente consumida pela população brasileira, seu uso como minimamente processada é facilitado., ${ }^{4,5}$ 
Segundo Gomes et al., ${ }^{6}$ hortaliças minimamente processadas são produtos pré-preparados através de descascamento, corte, sanitização, centrifugação e acondicionamento em embalagens que mantenham o produto em seu estado fresco, agregando a esse conceito, atributos de funcionalidade e valor.

Embora sejam muitos os benefícios, discute-se a segurança desses produtos, devido à incidência de microrganismos deteriorantes e patogênicos, que são veículos de doenças, e a perda do produto. Em razão da manipulação e das injúrias mecânicas, os produtos minimamente processados estão susceptíveis a contaminação, que consequentemente acelera a degradação e a perda da qualidade. ${ }^{7}$

Alimento seguro é a garantia do consumidor em adquirir um produto de qualidade e de seu interesse, agregando a isto, atributos de saúde e segurança. No entanto, substâncias que podem causar perigo à saúde humana não podem ser visualizadas externamente no momento da compra. ${ }^{5}$

A qualidade microbiológica dos alimentos minimamente processados está associada à presença de microrganismos deteriorantes, os quais atuam contribuindo negativamente com as características dos alimentos, como alterações sensoriais indesejáveis (cor, sabor, aroma), assim como a concentração de microrganismos patogênicos em quantidades capazes de causar algum dano á saúde do consumidor. Portanto, a segurança microbiológica é a ausência de toxinas microbianas e de microrganismos causadores de doenças veiculadas por alimentos, como as infecções alimentares, toxinfecções e intoxicações. ${ }^{8}$ Alimentos minimamente processados constituem um meio favorável ao crescimento microbiano, devido à perda da integridade do produto, resultando em tecidos lesados e com alto teor de umidade nos vegetais. ${ }^{5}$

Devido ao aumento no consumo de vegetais minimamente processados, a qualidade microbiológica desses produtos e a preocupação com as ocorrências de doenças transmitidas por alimentos (DTAs), e sendo a couve um vegetal de preferência entre os brasileiros, o presente trabalho teve por objetivo o estudo comparativo da couve minimamente processada e in natura, segundo aspectos de qualidade microbiológica.

\section{Metodologia}

A pesquisa foi realizada na central de abastecimento (CEASA), do centro da cidade de Vitória da Conquista-BA, onde foram selecionadas aleatoriamente dez barracas de hortifruti para a coleta das amostras. Cinco barracas estavam em um corredor e cinco em outro corredor, sendo classificadas em corredor 1 e corredor 2 (C1 e C2). Em cada barraca foi coletada uma amostra de couve in natura e outra de couve minimamente processada, totalizando dez amostras para cada produto. 
A coleta foi realizada em duas repetiçóes, com intervalo de dois dias para cada coleta, todas sob condições assépticas. Após a coleta das amostras, estas foram encaminhadas ao laboratório em bolsas térmicas com gelo e se mantiveram refrigeradas até o momento da análise. A análise microbiológica das couves realizou-se no laboratório de microbiologia da Faculdade de Tecnologia e Ciências (FTC) de Vitória da Conquista-BA. Todos os métodos seguiram as orientações do Instituto Adolfo Lutz e de Silva et al. ${ }^{10}$

As amostras foram coletadas em dois corredores ( $\mathrm{Cl}$ e C2), sendo que para cada um foram colhidas cinco amostras de couve minimamente processadas e a mesma quantidade para a couve in natura. Foram feitos "pools" de amostras para cada corredor, retirando-se 25g de cada amostra, totalizando uma massa de $125 \mathrm{~g}$.

Cada pool de amostra foi homogeneizado, sendo retirados $50 \mathrm{~g}$ e diluídos em $450 \mathrm{ml}$ de água peptonada tamponada esterilizada a $1 \%$ - diluição que corresponde a $10^{-1}$. Pelo fato de as primeiras análises de aeróbios mesófilos e Staphylococcus aureus apresentarem valores incontáveis, as amostras foram rediluídas a $10^{-2}$ - diluição feita coletando-se $1 \mathrm{ml}$ da amostra a $10^{-1}$ e diluindo em $9 \mathrm{ml}$ de água peptonada estéril em 1 erlenmeyer de $50 \mathrm{~mL}$.

As amostras foram inoculadas em placas de Petrifilm para aeróbios mesófilos, Staphylococcus aureus, coliforme totais, bolores e leveduras. O procedimento foi realizado levantando-se o filme da placa, onde foi adicionado no centro $1 \mathrm{ml}$ da diluição, cobrindo-a em seguida. Foi posicionado o difusor no centro da placa para que a amostra se distribuísse uniformemente. Incubaram-se as mesmas em estufa a $\pm 38^{\circ} \mathrm{C}$ por 48 horas.

\section{Resultados e discussão}

Neste estudo, as amostras de couve analisadas mostraram-se contaminadas com contagens microbianas elevadas na faixa de $10^{2}$ a $10^{5} \mathrm{UFC} / \mathrm{g}$, apresentando-se possivelmente fora do padrão para o consumo. A RDC nำ12/2001 da ANVISA ${ }^{11}$ não estabelece parâmetros microbiológicos para os microrganismos pesquisados, determinando apenas para Salmonella e coliformes termotolerantes.

Nas amostras analisadas, constatou-se a presença de todos os microrganismos pesquisados (aeróbios mesófilos, Staphylococcus aureus, coliformes totais, bolores e leveduras) em relação aos setores (C1 e C2) onde são comercializados (tabelas 1 e 2). 
Tabela 1. Valores microbiológicos (UFC/g) de couve minimamente processada em seus respectivos setores. Vitória da Conquista-BA, 2014.

\begin{tabular}{ccccc}
\hline $\begin{array}{c}\text { Local/ } \\
\text { Repetição }\end{array}$ & $\begin{array}{c}\text { Aeróbios } \\
\text { Mesófilos } \\
\left(10^{-2}\right)\end{array}$ & $\begin{array}{c}\text { Staphylococcus } \\
\text { aureus } \\
\left(10^{-2}\right)\end{array}$ & $\begin{array}{c}\text { Coliformes } \\
\text { Totais } \\
\left(10^{-1}\right)\end{array}$ & $\begin{array}{c}\text { Bolores e } \\
\text { Leveduras } \\
\left(10^{-1}\right)\end{array}$ \\
\hline C1 R1 & Incontáveis & $1,2.10^{4}$ & Incontáveis & $2,25.10^{2}$ \\
C1 R2 & Incontáveis & $7,2.10^{4}$ & $8,7.10^{3}$ & $1,9.10^{2}$ \\
C2 R1 & Incontáveis & $8,25.10^{3}$ & $5,8.10^{3}$ & $5,25.10^{2}$ \\
C2 R2 & Incontáveis & $7,2.10^{4}$ & $1,68.10^{4}$ & $3,25.10^{2}$ \\
\hline
\end{tabular}

C1 e C2 (Setores de coleta das amostras); R1 e R2 (Repetições).

Tabela 2. Valores microbiológicos (UFC/g) de couve in natura em seus respectivos setores. Vitória da Conquista-BA, 2014.

\begin{tabular}{ccccc}
\hline $\begin{array}{c}\text { Local/ } \\
\text { Repetição }\end{array}$ & $\begin{array}{c}\text { Aeróbios } \\
\text { Mesófilos } \\
\left(10^{-2}\right)\end{array}$ & $\begin{array}{c}\text { Staphylococcus } \\
\text { aureus } \\
\left(10^{-2}\right)\end{array}$ & $\begin{array}{c}\text { Coliformes } \\
\text { Totais } \\
\left(10^{-2}\right)\end{array}$ & $\begin{array}{c}\text { Bolores e } \\
\text { Leveduras } \\
\left(10^{-2}\right)\end{array}$ \\
\hline C1 R1 & $1,96.10^{5}$ & $2.10^{3}$ & $1,4.10^{4}$ & $2.10^{2}$ \\
C1 R2 & $1,3.10^{5}$ & $1,5.10^{4}$ & $4,3.10^{3}$ & $1,9.10^{2}$ \\
C2 R1 & $1,65.10^{5}$ & $5,25.10^{3}$ & $9,8.10^{3}$ & $1,7.10^{2}$ \\
C2 R2 & $1,6.10^{5}$ & $5,3.10^{3}$ & $9,35.10^{3}$ & $1,65.10^{2}$ \\
\hline
\end{tabular}

C1 e C2 (Setores de coleta das amostras); R1 e R2 (Repetições)

A análise de aeróbios mesófilos nas amostras de couve minimamente processadas apresentou resultados incontáveis tanto em C1, quanto em C2. A RDC nำ 12/01-ANVISA ${ }^{11}$ não determina parâmetros aceitáveis para aeróbios mesófilos, mas segundo Franco \& Landgraf, ${ }^{12}$ contagem elevada deste grupo de bactérias demonstra uso de matéria-prima contaminada e processamento insatisfatório. Ravelli et al. ${ }^{13}$ detectaram contaminação microbiana em legumes minimamente processados, variando de 1,0 .107 a 7,3 .10³ UFC/g para aeróbios mesófilos. 
Em relação ao Sthaphylococcus aureus, este apresentou alta contagem microbiana em todas as amostras analisadas, indicando perigo potencial à saúde, devido à possível presença da enterotoxina estafilocócica. ${ }^{12}$ Valores idênticos de $S$. aureus foram encontrados na segunda repetição, em C1 e C2. Porém o valor mínimo ocorreu na primeira amostra de C2. O valor médio encontrado em todas as amostras correspondeu a 4,1 .10 $\mathrm{UFC} / \mathrm{g}$. Segundo Forsythe, ${ }^{14}$ alimentos contaminados com valores $\geq$ a $10^{5}$ de $S$. aureus produzirão toxinas, levando a sintomas de contaminação estafilocócica.

Trabalho realizado por Assis \& Uchida ${ }^{15}$ evidenciou valores > $1.100 \mathrm{NMP} / \mathrm{g}$ de coliformes totais em couves fatiadas comercializadas em supermercados de Campo Mourão-PR, porém no presente estudo os valores foram superiores em todas as amostras, sendo incontáveis na primeira amostra em C1. A RDC nำ 12/01-ANVISA ${ }^{11}$ estabelece níveis aceitáveis apenas para coliformes termotolerantes.

Quanto aos bolores e leveduras, as amostras mostraram-se mais contaminadas em C2, com média de 3,1. $10^{2} \mathrm{UFC} / \mathrm{g}$. Valores superiores entre 4,1 .10 a 3,7 .10 $\mathrm{UFC} / \mathrm{g}$ estiveram presentes em cenoura e repolho ralados comercializados em supermercados no município de Fortaleza-CE durante pesquisa realizada por Bruno et al. ${ }^{16}$

As amostras de couve in natura (tabela 2) obtiveram resultados positivos para aeróbios mesófilos, Staphylococcus aureus, coliformes totais, bolores e leveduras. No entanto, as amostras de couve minimamente processadas mostraram-se mais contaminadas do ponto de vista microbiológico, em comparação com as amostras de couve in natura.

Na tabela 2, é possível visualizar a contagem de aeróbios mesófilos que apresentou uma média de 1,6. $10^{5} \mathrm{UFC} / \mathrm{g}$ em couves in natura, sendo que, para as couves minimamente processadas, os resultados não foram obtidos devido à grande quantidade de bactérias encontradas. Conforme Mogharbel, ${ }^{17}$ alimentos que têm a superfície cortada são mais susceptíveis ao ataque por microrganismos. Estes estão presentes no próprio tecido vegetal ou provêm do solo e ar; além disso, a excessiva manipulação e a liberação de nutrientes no processo de corte favorecem uma possível contaminação.

Em relação às amostras de couve in natura contaminadas por Staphylococcus aureus, a média encontrada entre os setores e as repetições foi de 6,9 .103 UFC/g, sendo que o pool de amostras com maior número de colônias esteve em C1 na segunda repetição. A presença deste microrganismo indica contaminação por manipulação e condições sanitárias das superfícies em contato com o alimento. ${ }^{12}$ No entanto, em comparação com as couves minimamente processadas, a amostra mostrou-se menos contaminada, pois observa-se na tabela 1 uma média de 4,1 .10 $\mathrm{UFC} / \mathrm{g}$ de Staphylococcus aureus. 
Os valores de coliformes totais nas couves in natura apresentaram quantidade maior em comparação com as couves minimamente processadas, com média de 9,3 .10³ UFC/g, enquanto os resultados referentes às couves minimamente processadas apresentaram média de 7,8 $10^{3}$ UFC/g. Segundo Mogharbel, ${ }^{17}$ o grupo dos coliformes totais é bastante comum em alimentos, por se originar do próprio solo de cultivo e estar envolvido na microbiota normal se cultivado em solo livre com material fecal. Portanto, são indicadores de higiene dos processos, e quando encontrados em níveis elevados, indicam risco de veiculação de outros patógenos.

Os bolores e leveduras estiveram presentes em todas as amostras representados na tabela 2, quantificando uma média de 1,8 .10² UFC/g. Em comparação com a tabela 1, evidencia-se menor teor de contaminação por estes microrganismos. As amostras de couve minimamente processadas apresentaram média de 3,1 .10² UFC/g. De acordo Mogharbel, ${ }^{17}$ a presença de bolores e leveduras em números consideráveis é indicativa de absorção de umidade no processamento do alimento.

A Tabela 3 apresentauma comparação da média de valores microbiológico encontrados nas amostras de couves minimamente processada e in natura,coletadas em C1 e C2, em duas repetições.

Tabela 3. Análise microbiológica comparativa (UFC/g) de amostras de couve minimamente processada e in natura. Vitória da Conquista-BA, 2014.

\begin{tabular}{cccccc}
\hline $\begin{array}{c}\text { Amostras } \\
\text { de couve }\end{array}$ & $\begin{array}{c}\text { Local/ } \\
\text { Repetição }\end{array}$ & $\begin{array}{c}\text { Aeróbios } \\
\text { Mesófilos } \\
\left(10^{-2}\right)\end{array}$ & $\begin{array}{c}\text { Staphylococcus } \\
\text { aureus } \\
\left(10^{-2}\right)\end{array}$ & $\begin{array}{c}\text { Coliformes } \\
\text { Totais } \\
\left(10^{-1}\right)\end{array}$ & $\begin{array}{c}\text { Bolores e } \\
\text { Leveduras } \\
\left(10^{-1}\right)\end{array}$ \\
\hline Processada & C1,2/R1,2 & Incontáveis & $4,1.10^{4}$ & $7,8.10^{3}$ & $3,1.10^{2}$ \\
In Natura & C1,2/R1,2 & $1,6.10^{5}$ & $6,9.10^{3}$ & $9,3.10^{3}$ & $1,8.10^{2}$ \\
\hline
\end{tabular}

C1,2 (locais); R1,2 (repetições).

As duas amostras de couve (processada e in natura) mostram-se contaminadas, com altas contagens microbianas variando de $10^{2}$ a $10^{5} \mathrm{UFC} / \mathrm{g}$ (tabela 3). No entanto, com exceção dos coliformes totais, pode-se observar discreto aumento nos valores relacionados às amostras de couve minimamente processada. Segundo Bruno et al., ${ }^{16}$ a contaminação de produtos minimamente processados pode ocorrer durante as operações de corte e fatiamento, devido à presença de patógenos nas superfícies da matéria-prima ou nas mãos de manipuladores. Com isso, o manuseio de equipamentos em condições insatisfatórias de higiene, associado ao aumento dos danos ao tecido, favorecem a população microbiana em vegetais. 


\section{Conclusão}

Foi possível concluir que as amostras de couve comercializadas encontram-se impróprias para o consumo, devido à grande quantidade de microrganismos encontrados.

Os microrganismos analisados neste estudo podem ser considerados indicativos de falta de controle higiênico-sanitário, sendo imprescindíveis mudanças no que se refere a manipulação, armazenamento e acondicionamento desses produtos.

A população deve ser esclarecida quanto à importância de lavar e sanitizar bem as hortaliças antes do consumo, o que contribui para a redução ou erradicação desses microrganismos, assim como previne quanto aos riscos de DTAs.

\section{Referências}

1. Empresa Brasileira de Pesquisa Agropecuária-Embrapa. Couve [Internet]. 2006. Acesso em: 05 abr. 2014. Disponível em: http://www.cnph.embrapa.br/hortalicasnaweb/couve.html

2. Moretti CL, Carnelossi MAG, Silva EO, Puschmann R. Processamento mínimo de couve. Brasília: Embrapa Hortaliças, 2000. 3 p. Comunicado Técnico, 13. Acesso em: 03 abr. 2014. Disponível em: http://bbeletronica.cnph.embrapa.br/2000/cot/cot_13.pdf

3. Oliveira-Calheiros K, Canniatti-Brazaca SG, Souza MC. Avaliação da disponibilidade do ferro em dieta complementada com couve manteiga. Alim. Nut. 2008; 19(1):37-42.

4. Carnelossi MAG, Silva EO, Campos RS, Soares NFF, Minim VPR, Puschmann R. Conservação de folhas de couve minimamente processadas. Revista Brasileira de Produtos Agroindustriais 2002; 4(2):149-155.

5. Santos APR, Junqueira AMR. Gestão da qualidade na couve minimamente processada no distrito federal: o caso da agroindústria Machadinho. Revista Brasileira de Produtos Agroindustriais 2012; 14(4):337-352.

6. Gomes CAO, Alvarenga ALB, Freire Junior M, Cenci SA. Hortaliças minimamente processadas. Brasília: Embrapa Informação Tecnológica; 2005. 34 p.

7. Moretti CL. Manual de processamento mínimo de frutas e hortaliças. Brasília: Embrapa Hortaliças; 2007.

8. Vanetti MCD. Segurança microbiológica em produtos minimamente processados. In: Resumos do $3^{\circ}$ Encontro nacional sobre processamento mínimo de frutas e hortaliças 2004, Viçosa, MG. Viçosa: UFV; 2004. p. 30-32.

9. Instituto Adolfo Lutz. Normas analíticas do Instituto Adolfo Lutz. Métodos químicos e físicos para análise de alimentos. São Paulo: IMESP; 2008. 
10. Silva N, Junqueira VCA, Silveira NFA, Taniwaki MH, Santos RFS, Gomes RAR. Manual de métodos de análise microbiológica de alimentos e água. 4ª ed. São Paulo: Livraria Varela; 2010.

11. Brasil. Resolução RDC n. 12, de 02 de janeiro de 2001. Aprova o regulamento técnico sobre os padrões microbiológicos para alimentos. Diário Oficial da União, 10 jan. 2001.

12. Franco BDGM, Landgraf M. Microbiologia dos alimentos. São Paulo: Atheneu; 2008.

13. Ravelli MN, Novaes APT, Nascimento GGF. Análise microbiológica de hortaliças minimamente processadas e comercializadas no município de Piracicaba, SP. Revista Higiene Alimentar 2010; 24(184/185):110-114. Acesso em: 01 abr. 2014. Disponível em: http://www.unimep.br/phpg/ mostraacademica/anais/4mostra/pdfs/21.pdf

14. Forsythe SJ. Microbiologia da segurança alimentar. Porto Alegre: Artmed; 2002.

15. Assis LLR, Uchida NS. Análise da qualidade microbiológica de hortaliças minimamente processadas comercializadas em Campo Mourão, PR. Brazilian Journal of Surgery and Clinical Research 2013; 5(3):17-22.

16. Bruno LM, Queiroz AAM, Andrade APC,Vasconcelos NM, Borges MF. Avaliação microbiológica de hortaliças e frutas minimamente processadas comercializadas em Fortaleza, CE. B. CEPPA 2005; 23(1):75-84.

17. Mogharbel ADI. Validação do emprego de instrumentos de coleta de dados, alface e manipuladores como indicadores de boas práticas em lanchonetes [tese]. Curitiba: Programa de doutorado em Tecnologia de Alimentos de Curitiba; 2007.

Recebido: 02/12/2014

Revisado: 03/3/2015

Aprovado: $11 / 4 / 2015$ 
